\title{
Do Women Change Their Drinking Behaviors While Trying to Conceive? An Opportunity for Preconception Counseling
}

\author{
Suzanne Tough, PhD; Karen Tofflemire, MSc; Margaret Clarke, MD; and Christine Newburn-Cook, PhD
}

Background: Prenatal alcohol exposure is a leading cause of preventable mental retardation and developmental disabilities, including fetal alcohol syndrome. Current medical guidelines recommend that no alcohol should be consumed over the period of conception and throughout pregnancy. Although the majority of women reduce alcohol consumption when they realize they are pregnant, this recognition may not occur until well into the first trimester, potentially impacting embryonic development.

Objectives: To describe and assess changes in patterns of women's alcohol use between the preconception, pre-pregnancy recognition and post-pregnancy recognition time periods. Secondly, to describe characteristics of women consuming any alcohol and those binge drinking during pre- and post-pregnancy recognition periods.

Methods: Computer assisted telephone interviews were conducted with 1042 women who had recently delivered a baby in urban Alberta, Canada. Differences in consumption patterns between time periods were analyzed using analysis of variance and Chi-square tests. Characteristics of those drinking both before and after pregnancy recognition were analyzed using logistic regression.

Results: Eighty percent of women reported alcohol consumption pre-conceptually, $50 \%$ pre-pregnancy recognition and $18 \%$ post-pregnancy recognition. Binge drinking was reported by $32 \%, 11 \%$ and $0 \%$ for preconception, pre-pregnancy recognition and post-pregnancy recognition periods, respectively. Alcohol consumption patterns (i.e., the mean number of drinks per drinking day and week) did not differ significantly between preconception and pre-pregnancy recognition periods but did significantly drop after pregnancy recognition $(p<0.00 \mathrm{I})$. Alcohol use during the period of pre-pregnancy recognition was higher among those not planning a pregnancy, not using assisted reproductive technology, of higher income, without a history of miscarriage, who were Caucasian, and who used tobacco. Binge drinking was higher among women not planning a pregnancy, those who used tobacco, and those with low self-esteem. Women continuing to drink small amounts of alcohol after pregnancy recognition were more likely to be between the ages of 30-39 years, be Caucasian and use tobacco.

Conclusion: Preconception and "well-women" counseling strategies would be improved by increasing the emphasis on the risks of alcohol use during periods when pregnancy can occur.

Keywords: Alcohol consumption; Preconception counseling; Pregnancy

$\mathrm{T}$

here are limited data on alcohol use over the course of pregnancy, and since no pattern of consumption or lower limit of alcohol exposure has been found to be safe, medical guidelines recommend abstinence during pregnancy and while attempting to conceive. ${ }^{1,2}$ In 1994, US surveys suggested that $14 \%$ of pregnant women reported alcohol use in the past month, and recent Canadian data revealed that $14.6 \%$ of mothers reported drinking any alcohol during pregnancy. 3,4 Unfortunately, accurate assessments of alcohol use may be hampered by the social stigma associated with reporting alcohol consumption, different methods of assessment and unclear definitions of when pregnancy began. 
Indeed, recent evidence suggests that, depending on the screening tool utilized, rates of alcohol use among pregnant women range between $21 \%$ to $70 \%{ }^{5}$ In addition to more accurate information about the prevalence of maternal alcohol use, the development of relevant preconception health strategies also requires an understanding of when fetal alcohol exposure is most likely to occur and how women currently behave in relationship to guidelines recommending alcohol abstinence during pregnancy.

In preparation for a healthy pregnancy, women are encouraged to review their medication use, their folic acid intake and their lifestyle choices, such as tobacco use and alcohol consumption. 6 A recent study found that $98 \%$ of Canadians believed that the more alcohol a pregnant woman drank, the more likely it would be that the baby would be harmed. ${ }^{7}$ Although the majority of women reduce alcohol consumption when they realize they are pregnant, this may not occur until well into the first trimester. ${ }^{8}$

Prenatal alcohol exposure is one of the leading causes of neurodevelopmental deficits in children, including those of fetal alcohol spectrum disorder (FASD). 9,10 The effects of alcohol on the fetus are likely influenced by the timing and amount of alcohol consumed, as well as by maternal metabolism and fetal genetics. ${ }^{11}$ Features of fetal alcohol syndrome (FAS), a collection of the most severe abnormalities caused by moderate to excessive maternal alcohol consumption, include pre- and postnatal growth deficiencies, characteristic craniofacial dysmorphology and varying degrees of central nervous system dysfunction. ${ }^{12,13}$ Equally debilitatating are mental and behavioral impairments that may occur in the absence of craniofacial abnormalities. ${ }^{10}$ The estimated global incidence of FAS is 0.97 per 1000 live births. ${ }^{14}$

When women are asked to describe their lifestyle habits during pregnancy, the beginning of pregnancy is often poorly defined. ${ }^{15,16}$ The accuracy of any overall measure of alcohol consumption during pregnancy is dependent on the individual's interpretation of when pregnancy began and may also be influenced by recall bias. Some women will report on consumption with reference to the time in which they knew they were pregnant, while others may report from the time of conception. ${ }^{8}$ Consequently, there is a lack of clear information on women's alcohol consumption during the early period of embryonic development.

It was hypothesized that the majority of women do not change their alcohol use patterns between the periods of preconception and pregnancy recognition, potentially exposing the fetus to alcohol in the early developmental stages. The purpose of this study was to assess and describe the changes in the patterns of women's alcohol use between the periods of preconception, pre-pregnancy recognition and post-pregnancy recognition, particularly as they relate to pregnancy planning. Secondly, this analysis sought to describe characteristics of women who consume any alcohol and those who binge drink during the periods of pre- and post-pregnancy recognition.

\section{Methods}

\section{Participants and setting}

Women over the age of 18 years were randomly selected from regional notice of birth databases by a computer-generated program. Primiparous women were identified and contacted within 3 months of delivery. Primiparous women were selected to avoid confounding of pregnancy-related behavior and knowledge of risks by previous experience with childbirth and parenting. Women were eligible for participation in the study if they delivered in either Calgary or Edmonton, Alberta, two large urban health regions serving populations of approximately one million each.

Participants were interviewed over the telephone by two female interviewers with content training related to maternal and child health. No incentive to participate was offered. This investigation received ethics approval from the University of Alberta and the Conjoint Ethics Board at the University of Calgary and the Calgary Health Region. All participants provided written consent (focus groups and pilot testing) or verbal consent (telephone interview) prior to participation.

\section{Survey}

Based on information from focus groups, previous surveys and expert input, a survey was designed specifically for this study. The questions were pilot tested with women of childbearing age who were not part of this study. These results were used to ensure that the questions were clearly written and non-offensive, that the duration of the survey was acceptable, and to resolve unclear wording. The survey contained the following sections: 1) socio-demographic characteristics of the woman and her partner, including education, employment, and income; 2) lifestyle factors, including tobacco, alcohol, and drug use; 3) medical and reproductive history from the current and past pregnancies; 4) factors women considered prior to starting their family, such as financial stability and career goals; 5) knowledge of pregnancy-related risks, such as increasing maternal age and alcohol use; and 6) self-esteem, measured by the Rosenberg Self-Esteem Scale. ${ }^{17}$

The Rosenberg Self-Esteem Scale generally has high reliability for assessing self-esteem; test-retest correlations are typically within the range of 0.82 to 0.88 .18 Scores range from 0 to 40, with higher ones indicating more positive self-esteem. However, because self-esteem is a generally stable characteristic in adults, it is not easily manipulated as an outcome. ${ }^{18,19}$ Therefore, we classified our results as being above or below the median score.

The face and content validity of the survey was ensured through focus group testing, pilot surveys, and review by medical experts. Data were collected by two experienced interviewers using a computer-assisted telephone interview 
Table 1. Characteristics of participants $(n=1042)$.

\begin{tabular}{|c|c|}
\hline Characteristic & $\begin{array}{c}\text { Frequency } \\
\text { N (\%) }\end{array}$ \\
\hline \multicolumn{2}{|l|}{ Age at conception } \\
\hline$<25$ years & $163(15.7)$ \\
\hline $25-29$ & $234(22.6)$ \\
\hline $30-34$ & $275(26.5)$ \\
\hline $35-39$ & $328(31.6)$ \\
\hline $40+$ & $37(3.6)$ \\
\hline \multicolumn{2}{|l|}{ Education completed } \\
\hline$<$ High school & $30(2.9)$ \\
\hline High school & $260(25.0)$ \\
\hline Post secondary & $633(60.8)$ \\
\hline Post graduate & $118(11.3)$ \\
\hline \multicolumn{2}{|l|}{ Annual family income (Canadian) } \\
\hline$<\$ 32,100$ & $91(9.1)$ \\
\hline$\$ 32,100-\$ 51,300$ & $140(14.0)$ \\
\hline$\$ 51,301-\$ 72,000$ & $194(19.4)$ \\
\hline$\$ 72,001-\$ 101,300$ & $280(28.0)$ \\
\hline$>\$ 101,300$ & $295(29.5)$ \\
\hline \multicolumn{2}{|l|}{ Marital status } \\
\hline Married/common law & $972(93.3)$ \\
\hline Single & $70(6.7)$ \\
\hline \multicolumn{2}{|l|}{ Maternal ethnicity } \\
\hline Not Caucasian & $174(16.7)$ \\
\hline Caucasian & 867 (83.3) \\
\hline \multicolumn{2}{|l|}{ Planning pregnancy } \\
\hline Yes & 835 (80.3) \\
\hline No & 205 (19.7) \\
\hline \multicolumn{2}{|l|}{ First pregnancy } \\
\hline Yes & $886(85.1)$ \\
\hline No & $155(14.9)$ \\
\hline \multicolumn{2}{|l|}{ Previous miscarriage } \\
\hline Yes & $92(8.8)$ \\
\hline No & $950(91.2)$ \\
\hline \multicolumn{2}{|l|}{ Previous abortion } \\
\hline Yes & $68(6.5)$ \\
\hline No & $976(93.5)$ \\
\hline \multicolumn{2}{|l|}{ Used assisted reproductive technology } \\
\hline Fertility medications & $71(6.8)$ \\
\hline Medications and in vitro fertilization and/or ICSI & $56(5.4)$ \\
\hline None & $915(87.8)$ \\
\hline \multicolumn{2}{|l|}{ Rosenberg Self-Esteem Scale } \\
\hline Mean (SD) & $23.6(4.24)$ \\
\hline \multicolumn{2}{|l|}{ Smoke } \\
\hline Yes & $229(22.0)$ \\
\hline No & $813(78.0)$ \\
\hline
\end{tabular}

ICSI, intracytoplasmic sperm injection.

Note: Frequencies may vary due to missing cases. over a 15-month period between July 2002 and September 2003. Data were collected outside of a clinical context in a non-threatening way by interviewers unfamiliar with the medical history of the participant to minimize bias and more accurately assess patterns of alcohol consumption prior to pregnancy recognition. ${ }^{20}$ Interviews were closely monitored by the project coordinator who was available to the interviewers at all times. Participants took up to 40 minutes to complete the surveys.

Specific alcohol measures collected on the survey

The pre-pregnancy recognition period was defined as the time period in which a woman was pregnant but had not yet recognized the pregnancy. This time period was calculated in weeks of gestation according to the answer provided to the following question, "How many weeks pregnant were you when your pregnancy was confirmed either as a result of a missed period, a home pregnancy test, or by confirmation from your physician or midwife?"

Participants were asked 19 questions related to alcohol consumption. Frequency of alcohol consumption was assessed by asking, "How many times per week did you usually have an alcoholic drink?" The quantity of alcohol was assessed by asking, "On the days that you had an alcoholic drink, how many drinks did you usually have?" One standard alcoholic drink was defined as one $341 \mathrm{ml}(12 \mathrm{oz})$ bottle of beer, one $341 \mathrm{ml}$ (12 oz) cooler or cider, one $142 \mathrm{ml}(5 \mathrm{oz})$ glass of table wine $(12 \%$ alcohol), or one $43 \mathrm{ml}(1.5 \mathrm{oz})$ serving of spirits. Measures of quantity and frequency of alcohol consumption were obtained for three separate time periods: 1) 6 months prior to pregnancy, 2) the pre-pregnancy recognition period, and 3) the post-pregnancy recognition period. Questions regarding binge drinking were also asked for these three time periods. Binge drinking was defined as the consumption of 5 or more drinks during a 24-hour period. Additional questions pertaining to participants' discussions with their physicians concerning alcohol consumption and pregnancy were also asked.

\section{Statistical analysis}

For alcohol consumption patterns within each period of interest, women were categorized as either low or high-risk drinkers. High-risk drinkers were defined as women consuming, on average, nine or more drinks per week and/or participating in binge drinking. ${ }^{21}$ High or low-risk drinking habits, as well as the proportion of women participating in binge drinking were compared between preconception, pre-pregnancy recognition and post-pregnancy recognition periods using a Chi-square test. Additionally, the mean number of drinks per drinking day (i.e., the quantity of alcohol consumed), the mean number of drinks per week (i.e., the frequency of alcohol consumption) and the mean number of binge drinking episodes were compared between the three time periods using a one-way analysis of variance followed by a multiple comparisons procedure using the Scheffe method. Additionally, the mean number of drinks consumed per drinking day was compared between those who 
Table 2. Alcohol consumption patterns for women consuming any alcohol during the preconception, pre-pregnancy recognition and post-pregnancy recognition periods.

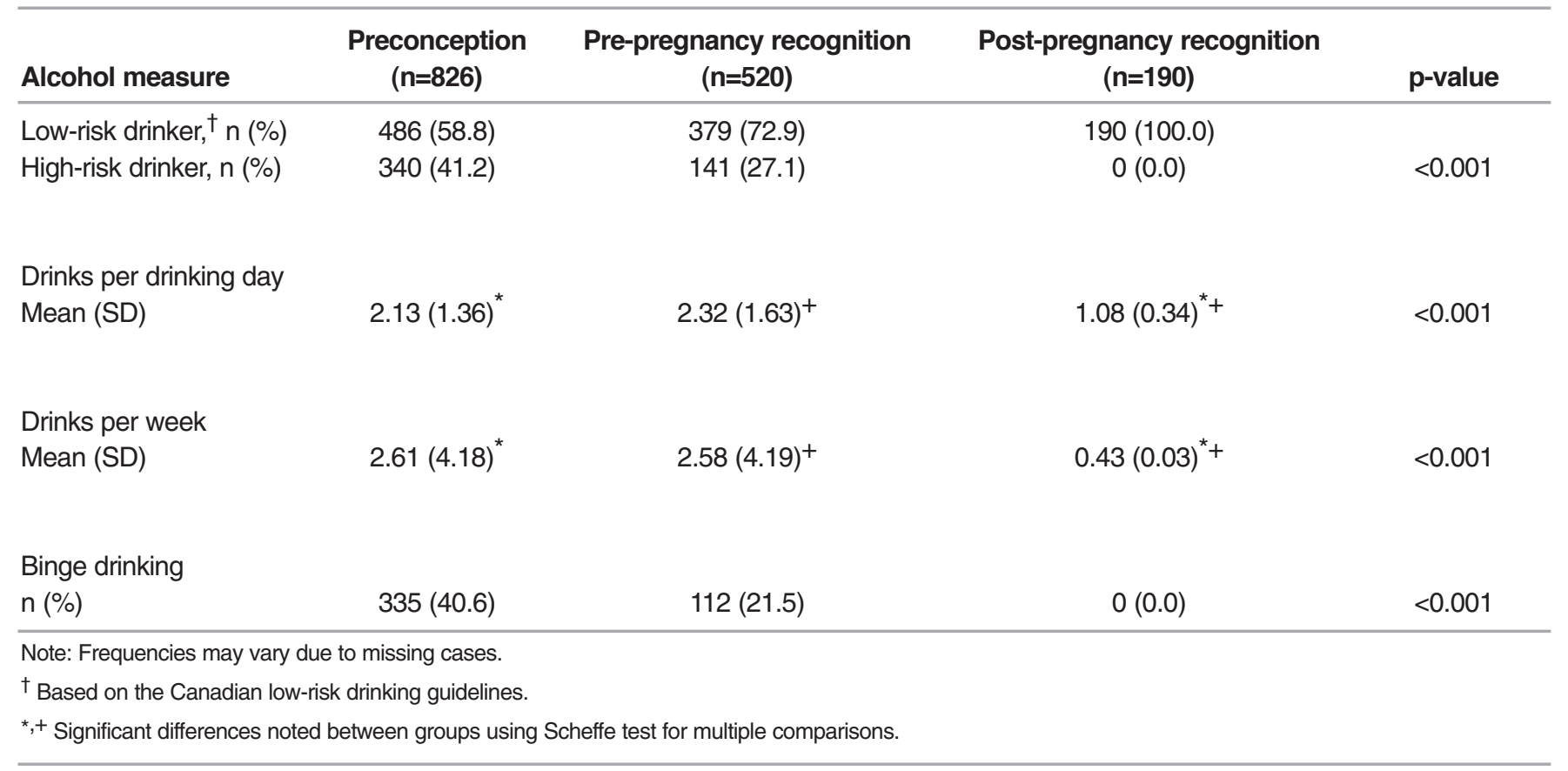

planned a pregnancy and those who did not plan a pregnancy using an independent t-test. Results were considered statistically significant if $\mathrm{p} \leq 0.05$.

Maternal characteristics of non-drinkers (i.e., women completely abstaining from alcohol) and drinkers (i.e., those consuming any alcohol) were compared for pre- and post-pregnancy recognition time periods using Chi-square tests. Data were also analyzed comparing non-binge drinkers (i.e., those without binge episodes) and binge drinkers. A difference was considered statistically significant if $\mathrm{p} \leq 0.05$. Subsequently, three logistic regression models were created using a forward method to describe the independent characteristics of women who were drinkers compared to those who were not drinkers. One model was created for drinkers compared to non-drinkers during the pre-pregnancy recognition period, another model for drinkers compared to non-drinkers during the post-pregnancy recognition period, and another for binge drinkers compared to non-binge drinkers during the pre-pregnancy recognition period. Confounding and interaction of variables were evaluated. Variables were entered into the model building process in the following order: planning of pregnancy, social/environmental factors, prenatal history, and lastly, demographic predictors. Adjusted odds ratios and 95\% confidence intervals were calculated.

\section{Results}

The overall response rate was 72\% (1044/1450), of which all but two provided some information on alcohol consumption. Table 1 provides characteristics of the participants. Thirty-five percent were aged 35 years or older, and $72 \%$ had received postsecondary education or training. The majority were married or common-law (93\%) and Caucasian (83\%).

Table 3. Average alcohol consumption (i.e., mean drinks per drinking day) during the preconception and pre- and post-pregnancy recognition periods by pregnancy planning.

\begin{tabular}{lcc}
\hline $\begin{array}{l}\text { Mean drinks per drinking day } \\
\begin{array}{l}\text { Preconception } \\
(n=825)\end{array}\end{array}$ & $\begin{array}{c}\text { Planning pregnancy } \\
\text { Mean (SD, range) }\end{array}$ & $\begin{array}{c}\text { Not planning pregnancy } \\
\text { Mean (SD, range) }\end{array}$ \\
$\begin{array}{l}\text { Pre-pregnancy recognition } \\
(n=520)\end{array}$ & $1.98(1.12)$ & $2.74(1.93)$ \\
$\begin{array}{l}\text { Post-pregnancy recognition } \\
(n=190)\end{array}$ & $2.21(1.50)$ & $2.65(1.92)$ \\
\hline
\end{tabular}

Note: Frequencies may vary due to missing cases. 
Eighty percent of the participants had planned this pregnancy. Although this was the first live birth for all women, $15 \%$ had experienced a previous pregnancy. Twelve percent of the women had used some form of assisted reproduction for this pregnancy. The mean time between conception and the recognition of the pregnancy (i.e., the period of pre-pregnancy recognition) was 5.02 weeks (SD 2.72, range 1 to 28 weeks).

\section{Alcohol consumption patterns}

Ninety-nine percent of the participants knew alcohol was not recommended during pregnancy. Eighty percent reported consuming some alcohol 6 months prior to the pregnancy, with approximately $60 \%$ of these women reporting patterns of low-risk drinking and $40 \%$ reporting binge drinking. Fifty percent reported drinking some alcohol during the pre-pregnancy recognition period, with $73 \%$ of these women reporting low-risk consumption patterns and $22 \%$ reporting at least one occasion of binge drinking. Eighteen percent of the participants reported drinking some alcohol after recognition of the pregnancy (all low-risk patterns), with none of these women reporting binge drinking (table 2).
Alcohol consumption patterns were compared between the time periods of preconception, pre-pregnancy recognition, and post-pregnancy recognition (table 2). There was no significant difference between the number of drinks per occasion or the frequency of drinking during the preconception period and the pre-pregnancy recognition period. However, consumption of alcohol significantly decreased after the pregnancy was confirmed (from 2.32 to 1.08 drinks per occasion and from 2.58 to 0.43 drinks per week).

Forty-seven percent of participants who were planning for pregnancy consumed some alcohol during the period of pre-pregnancy recognition compared to $53 \%$ of those not planning for pregnancy. Table 3 compares the mean number of drinks per drinking day between those who planned for pregnancy and those who did not plan. Among those consuming any alcohol in the 6 months prior to pregnancy, women who were planning a pregnancy drank significantly less than those not planning (1.98 vs. 2.74 drinks per occasion). Among those who consumed alcohol during the period of pre-pregnancy recognition, those who planned a pregnancy drank significantly

Table 4. Adjusted odds ratios for characteristics of women consuming versus not consuming alcohol during the period of pre-pregnancy recognition $(n=1042)$.

\begin{tabular}{|c|c|c|c|c|}
\hline Characteristic & $\begin{array}{c}\text { Drinker }(n=525) \\
n(\%)\end{array}$ & $\begin{array}{c}\text { Non-drinker }(\mathrm{n}=517) \\
\mathrm{n}(\%)\end{array}$ & Odds ratio & $95 \% \mathrm{Cl}$ \\
\hline \multicolumn{5}{|l|}{ Planned pregnancy } \\
\hline Yes & $388(46.9)$ & $439(53.1)$ & 1.00 & \\
\hline No & $137(66.8)$ & $68(33.2)$ & 2.31 & $1.56-3.40$ \\
\hline \multicolumn{5}{|c|}{ Annual family income (Canadian) } \\
\hline$<\$ 32,100$ & $46(50.5)$ & $45(49.5)$ & 1.00 & \\
\hline$\$ 32,100-\$ 51,300$ & $69(49.6)$ & $70(50.4)$ & 1.10 & $0.60-2.00$ \\
\hline$\$ 51,301-\$ 72,000$ & $90(46.9)$ & $102(53.1)$ & 1.31 & $0.73-2.34$ \\
\hline$\$ 72,001-\$ 101,300$ & $143(51.6)$ & $134(48.4)$ & 1.65 & $0.95-2.89$ \\
\hline$>\$ 101,300$ & $158(54.1)$ & $134(45.9)$ & 2.36 & $1.34-4.17$ \\
\hline \multicolumn{5}{|c|}{ Any assisted reproductive technology } \\
\hline Yes & $32(25.4)$ & $94(74.6)$ & 1.00 & \\
\hline No & $493(54.3)$ & $415(45.7)$ & 3.10 & $1.96-4.90$ \\
\hline \multicolumn{5}{|l|}{ Previous miscarriage } \\
\hline Yes & $33(35.9)$ & $59(64.1)$ & 1.00 & \\
\hline No & $492(52.2)$ & $450(47.8)$ & 2.34 & $1.41-3.90$ \\
\hline \multicolumn{5}{|l|}{ Smoke } \\
\hline Yes & $161(70.6)$ & $67(29.4)$ & 3.00 & $2.09-4.32$ \\
\hline No & $364(45.2)$ & $442(54.8)$ & 1.0 & \\
\hline \multicolumn{5}{|l|}{ Caucasian } \\
\hline Yes & $473(54.9)$ & $389(45.1)$ & 2.94 & $1.98-4.36$ \\
\hline No & $52(30.4)$ & 119 (69.6) & 1.00 & \\
\hline
\end{tabular}

Note: Frequencies may vary due to missing cases.

$\mathrm{Cl}$, confidence intervals. 
Table 5. Adjusted odds ratios for characteristics of women binge drinking versus those not binge drinking during the period of pre-pregnancy recognition among those who drank some alcohol during this period $(n=525)$.

\begin{tabular}{|c|c|c|c|c|}
\hline Characteristic & $\begin{array}{l}\text { Binge drinking }(n=112) \\
n(\%)\end{array}$ & $\begin{array}{l}\text { No binge drinking }(n=413) \\
n(\%)\end{array}$ & Odds ratio & $95 \% \mathrm{Cl}$ \\
\hline \multicolumn{5}{|l|}{ Planned pregnancy } \\
\hline Yes & $63(16.4)$ & 322 (83.6) & 1.00 & \\
\hline No & $49(35.8)$ & $88(64.2)$ & 2.18 & $1.37-3.48$ \\
\hline \multicolumn{5}{|l|}{ Smoke } \\
\hline Yes & $58(36.1)$ & 103 (63.9) & 2.50 & \\
\hline No & $54(15.0)$ & $307(85.0)$ & 1.00 & $1.58-3.94$ \\
\hline \multicolumn{5}{|l|}{ Self-esteem } \\
\hline Above median score & $46(16.7)$ & 229 (83.3) & 1.00 & \\
\hline Below median score & $66(27.2)$ & $177(72.8)$ & 1.58 & $1.01-2.46$ \\
\hline
\end{tabular}

less than those who did not plan (2.21 vs. 2.65 drinks per occasion). There were no differences noted in the amount of alcohol consumed once the pregnancy was confirmed between those who did or did not plan a pregnancy.

Characteristics of those who consumed any alcohol during the pre-pregnancy recognition period

Participants who consumed alcohol prior to pregnancy recognition did not differ from those who abstained from alcohol in terms of age, income or education level $(\mathrm{p}>0.05)$ (results not shown). In the bivariate analysis, compared to the non-drinkers, the drinkers were more likely (all $\mathrm{p}<0.001)$ to be single ( $9.7 \%$ vs. $3.7 \%)$, Caucasian $(90.1 \%$ vs. $76.6 \%)$ and tobacco users $(30.7 \%$ vs. $13.2 \%)$. Non-drinkers were more likely (all $\mathrm{p}<0.05)$ to have previously miscarried $(11.6 \%$ vs. $6.3 \%)$, to have planned the pregnancy $(86.6 \%$ vs. $73.9 \%)$, to have used fertility medications $(17.9 \%$ vs. $6.1 \%)$ and to have used in vitro fertilization ( $9.6 \%$ vs. $0.6 \%)$.

When a multivariate model was developed to assess the independent effect of predictor variables, it was found that participants who did not plan the pregnancy were 2.3 times more likely than those who did plan the pregnancy to consume alcohol during the period of conception (table 4). Annual income of more than $\$ 100,000$, non-use of assisted reproductive technology, no previous miscarriages, tobacco use and being Caucasian all predicted an increased likelihood of alcohol consumption during the period of conception (table 4). There were no interaction effects.

Characteristics of those who participated in binge drinking during the pre-pregnancy recognition period

Twenty-one percent $(112 / 522)$ of the participants who consumed alcohol (10.7\% of the entire study population) reported at least one binge drinking episode during the period of pre-pregnancy recognition. Among these women, the mean number of binge episodes was 2.45 (SD 3.15, range 1 to 20).
At the bivariate level (results not shown), binge drinkers were more likely than non-binge drinkers (all $\mathrm{p}<0.001$ ) to be younger, have a lower education and have a lower income. Binge drinkers were also more likely (all $\mathrm{p}<0.001)$ to be tobacco users (51.8\% vs. $25.1 \%)$, single ( $18.8 \%$ vs. $7.3 \%)$ and to have planned the pregnancy ( $43.8 \%$ vs. $21.5 \%$ ) compared to participants who did not binge drink. No differences were found for ethnicity, assisted reproductive technology use or past pregnancy experience.

When a multivariate model was developed to assess the independent effect of predictor variables, it was found that participants who did not plan the pregnancy were two times more likely to binge drink during the period of pre-pregnancy recognition than those who did plan the pregnancy (table 5). Tobacco use and having low self-esteem also predicted binge drinking before pregnancy recognition (table 5). No interaction effects were found.

Characteristics of those who consumed alcohol during the post-pregnancy recognition period

Participants who consumed alcohol after pregnancy recognition did not differ from those who did not consume alcohol in terms of education level, planning of pregnancy or self-esteem $(\mathrm{p}>0.05)$ (results not shown). In the bivariate analysis, compared to non-drinkers, drinkers were more likely (all $\mathrm{p}<0.001$ ) to use tobacco, to be Caucasian, to be between the ages of 30 and 39 years and to have a higher income.

When a multivariate model was developed to assess the independent effect of predictor variables, it was found that being between the ages of 30 and 39 years, using tobacco and being Caucasian all predicted an increased likelihood of alcohol consumption post-pregnancy recognition (table 6). No interaction effects were found. 


\section{Discussion}

Since the identification of FAS in North America in 1973, ${ }^{22}$ efforts to inform women of the risks of alcohol exposure to the fetus have been undertaken. As evidence of the effectiveness of these efforts, all women in this study were aware of these risks, and the majority stopped drinking alcohol once they realized they were pregnant. However, prior to recognizing their pregnancy, $13.5 \%$ of all women in this study were engaging in high-risk drinking patterns, including binge drinking, and an additional 36.4\% reported low-risk consumption patterns. The relatively high rates of alcohol consumption during the period of pre-pregnancy recognition are consistent with reported rates among non-pregnant women, which lend support to the veracity of these data. ${ }^{23}$ Previous research has suggested that $75 \%$ of US women consumed at least one alcoholic drink during pregnancy. ${ }^{24}$

The early stages of embryonic development are important periods for healthy development of the infant. Animal studies have highlighted the vulnerability of the central nervous system to ethanol-induced cytotoxicity at different embryonic stages. ${ }^{25}$ Mouse embryos exposed to ethanol in utero on gestational day 7 , which is equivalent to the third week of human gestation, exhibited craniofacial and midline forebrain deficiencies associated with FAS. ${ }^{26,27}$ In our study, the average length of time between conception and pregnancy recognition was 5 weeks. During this pre-pregnancy recognition period, there is sufficient opportunity for alcohol to potentially impact fetal development.

Although the majority of women in the current study planned for pregnancy, other studies have found that unplanned pregnancies represent $49 \%$ to $55 \%$ of all pregnancies. ${ }^{28,29}$ It should be noted that for the current study, the planning status of pregnancy was defined separately from the intended status of pregnancy. Intendedness reflects attitudes toward a pregnancy such as desire and timing, while planning reflects behavior, such as using birth control at the time of conception. ${ }^{30}$ The current study found that the majority of the women were not only planning for pregnancy $(80.3 \%)$ but also desired having the child $(90.3 \%)$ and felt the timing for having a child was convenient $(90.8 \%)$. When pregnancies are unplanned, mothers are less likely to receive preconception and prenatal care. ${ }^{31,32}$ Additionally, babies born to mothers who did not intend to become pregnant are at an increased risk for exposure to harmful substances including tobacco and alcohol. ${ }^{33}$ Therefore, it would seem that the planning status of pregnancy is an important construct for "well women" and preconception program planners and researchers. ${ }^{34}$

In this study, unplanned pregnancy was found to be associated with both binge drinking and higher average alcohol consumption $(\mathrm{p}<0.05)$. Likewise, other studies have shown that binge drinking is associated with an increase in the risk of unplanned and unprotected sexual activity. ${ }^{35,36}$ Thus, for women who are high-risk drinkers, including binge drinkers, counseling should address contraception, as well as a reduction in alcohol consumption. ${ }^{37}$

Almost half of all women in this study who were planning for pregnancy consumed some alcohol during the period of pre-pregnancy recognition. Furthermore, those who continued to drink during this period of pre-pregnancy recognition did not change the amount of alcohol consumed per drinking day from the amounts consumed 6 months prior to pregnancy. The finding that most women were planning a pregnancy but many did not abstain from alcohol nor reduce consumption patterns while trying to conceive lends support to the need for improvements in preconception and "well women" counseling strategies.

Table 6. Adjusted odds ratios for characteristics of women consuming versus not consuming alcohol post-pregnancy recognition $(n=1042)$.

\begin{tabular}{lcccc}
\hline Characteristic & $\begin{array}{c}\text { Drinker }(\mathbf{n}=\mathbf{1 9 1}) \\
\mathbf{n}(\%)\end{array}$ & $\begin{array}{c}\text { Non-drinker }(\mathbf{n}=\mathbf{8 5 1}) \\
\mathbf{n}(\%)\end{array}$ & Odds ratio & $\mathbf{9 5 \%} \mathbf{C l}$ \\
\hline $\begin{array}{l}\text { Maternal age (years) } \\
<25\end{array}$ & $23(14.1)$ & $140(85.9)$ & 1.00 & \\
$25-29$ & $32(13.7)$ & $202(86.3)$ & 1.19 & $0.63-2.23$ \\
$30-34$ & $54(19.6)$ & $222(80.4)$ & 1.99 & $1.12-3.52$ \\
$35-39$ & $74(22.5)$ & $255(77.5)$ & 2.35 & $1.34-4.10$ \\
$40+$ & $7(18.9)$ & $30(81.1)$ & 1.89 & $0.72-4.94$ \\
Smoke & & & & \\
Yes & $38(25.2)$ & $113(74.8)$ & 1.60 & $1.02-2.51$ \\
No & $153(17.1)$ & $740(82.9)$ & & \\
Caucasian & & & 2.00 & $1.20-3.52$ \\
Yes & $172(19.8)$ & $697(80.2)$ & 1.00 & \\
No & $19(10.9)$ & $155(89.1)$ & & \\
\hline
\end{tabular}

Note: Frequencies may vary due to missing cases.

$\mathrm{Cl}$, confidence intervals. 
Despite the fact that most women recognize that alcohol use during pregnancy is not advised, women appear to be uninformed of the potential consequences of alcohol exposure prior to pregnancy recognition. With increased emphasis on the risks of alcohol use when planning a pregnancy, preconception and "well women" counseling strategies may reduce the risk of unintended prenatal alcohol exposure.

Although it has been noted by medical professionals that preconception care can be beneficial to women of childbearing age and may have a positive effect on pregnancy outcome, ${ }^{38}$ barriers to the implementation of this care exist. Such barriers include a lack of time and financial resources to provide preconception counseling, a perceived lack of patient interest, a shortage of providers and limitations in provider training in the areas of addictions and substance abuse. ${ }^{38,39}$ Furthermore, the mechanism by which preconception counseling can influence alcohol use during the preconception period and the early stages of pregnancy has yet to be identified. In a recent Danish study, 40 it was noted that women's attitudes and actions concerning alcohol consumption during pregnancy were independent of their knowledge about the subject, a finding also confirmed in the present study. The Danish authors question whether pregnant women, and possibly healthcare professionals, are completely convinced that total abstinence is necessary during pregnancy. Indeed, a recent Canadian study found that those physicians recommending abstinence from alcohol versus moderate alcohol consumption during pregnancy were more likely than those not recommending abstinence $(p<0.05)$ to state that there is enough solid information about alcohol use and that clients are interested in the discussion of alcohol use. ${ }^{39}$

Several limitations exist within this study. In particular, ascertainment of alcohol consumption is very difficult as it is subject to over- and underestimation. As such, there are conflicting views on how and when it is best to interview a woman regarding alcohol exposure in pregnancy. Pregnant women are usually counseled not to use tobacco, alcohol or other drugs, and therefore may be more liable to misreport exposures. ${ }^{41}$ As this was a self-report survey, response bias may have influenced the reported data. However, the data were collected by non-clinical interviewers, were not linked to clinical care, and were not shared with health care providers or family members which improves the chance of unbiased reporting. 17

In addition, this was a retrospective study, so results should be interpreted in light of evidence that suggests that women who are interviewed retrospectively report higher levels of drinking during pregnancy than those who are interviewed antenatally. ${ }^{41,42}$ Finally, these data represent a sample of urban, mainly Caucasian women, and findings may not be generalizable to all populations. Repetition of this study in geographically and economically diverse areas with inclusion of a qualitative component to better understand the factors influencing alcohol use prior to pregnancy recognition may be helpful in the development of intervention programs or public health initiatives.

\section{Conclusion}

These data reveal that a large proportion of women are not changing their drinking behaviors, including the average amount of alcohol consumed per occasion, while trying to conceive, thus putting their developing child at risk for alcohol exposure during the early stages of embryonic development. These findings support the need for intervention programs and both "well women" and preconception counseling highlighting the necessity of reduced alcohol consumption while trying to conceive. Unplanned pregnancy was recognized as a major factor for not changing drinking habits during the period of conception. Hence, extra attention to "well women" and contraceptive counseling is warranted for those at an increased risk of binge drinking, including women who are smokers and have a lower self-esteem.

\section{Acknowledgments}

Infrastructure support was provided by the Calgary Health Region. The authors would like to acknowledge the following individuals for their contributions to this study: Monica Jack, Karen Benzies, Nonie Fraser-Lee, Alexandra Faber, Corine Frick, Reg Sauve and Ian Lange.

\section{References}

1. Alberta Medical Association. Guideline for the diagnosis of fetal alcohol syndrome (FAS). Available at:

http://www.albertadoctors.org/bcm/ama/amawebsite.nsf/AllDoc/87256DB000705C3F87256E0500553531 /\$File/FAS_DIAGNOSIS.PDF?OpenElement. Accessed March 24, 2006.

2. Alberta Medical Association. Preface to the prevention \& diagnosis of fetal alcohol syndrome (FAS). Available at: http://www.albertadoctors.org/bcm/ama/amawebsite.nsf/AllDoc/87256DB000705C3F87256E050055353E /\$File/FAS_PREFACE.PDF?OpenElement. Accessed March 24, 2006.

3. Centers for Disease Control and Prevention (CDC). Population-based prevalence of perinatal exposure to cocaine-Georgia, 1994. MMWR Morb Mortal Wkly Rep 1996;45:887-891.

4. Health Canada. Canadian Perinatal Health Report, 2003. Ottawa, ON: Minister of Public Works and Services Canada; 2003. Available at: http://www.phac-aspc.gc.ca/publicat/cphrrspc03/pdf/cphr-rspc03_e.pdf. Accessed March 24, 2006.

5. Clark KA, Dawson S, Martin SL. The effect of implementing a more comprehensive screening for substance use among pregnant women in North Carolina. Matern Child Health J 1999;3:161-166.

6. SOGC Clinical Practice-Obstetrics Committee. Clinical Practice Guideline No. 71: Healthy Beginnings: Guidelines for Care during Pregnancy and Childbirth. Ottawa, ON: Society of Obstetricians and Gynaecologists of Canada; 1998.

7. Environics Research Group Limited. Canadian Public Awareness of Fetal Alcohol Syndrome and Fetal Alcohol Effects Results of a National Survey. Ottawa, ON: Health Canada; 1999.

8. Kesmodel U. Binge drinking in pregnancy - frequency and methodology. Am J Epidemiol 2001;154:777-782.

9. Coles CD. Impact of prenatal alcohol exposure on the newborn and the child. Clin Obstet Gynecol 1993;36:255-266.

10. Riley EP, Mattson SN, Li TK, Jacobson SW, Coles CD, Kodituwakku PW, Adnams CM, Korkman MI. Neurobehavioral consequences of prenatal alcohol exposure: an international perspective. Alcohol Clin Exp Res 2003;27:362-373. 
11. Health Canada. Joint Statement: Prevention of Fetal Alchol Syndrome (FAS), Fetal Alcohol Effects (FAE) in Canada (Rep. No. H39-348/1996E). Ottawa, ON: Health Canada; 1996.

12. Streissguth AP, Barr HM, Martin DC. Offspring effects and pregnancy complications related to self-reported maternal alcohol use. Dev Pharmacol Ther 1982;5:21-32.

13. Astley SJ, Bailey D, Talbot C, Clarren SK. Fetal alcohol syndrome (FAS) primary prevention through fas diagnosis: II. A comprehensive profile of 80 birth mothers of children with FAS. Alcohol Alcohol 2000;35:509-519.

14. Abel EL. An update on incidence of FAS: FAS is not an equal opportunity birth defect. Neurotoxicol Teratol 1995;17:437-443.

15. Tolo KA, Little RE. Occasional binges by moderate drinkers: implications for birth outcomes. Epidemiology 1993;4:415-420.

16. Olsen J, Tuntiseranee P. Is moderate alcohol intake in pregnancy associated with the craniofacial features related to the fetal alcohol syndrome? Scand J Soc Med 1995;23:156-161.

17. Rosenberg M. Society and the adolescent self-image. Princeton, New Jersey: Princeton University Press; 1965.

18. Rosenberg M. Conceiving the Self. Malabar, Florida: Krieger; 1986.

19. Blascovich J, Tomaka J, Tomaka J. Measures of self-esteem. In: Robinson JP, Shaver PR, Wrightsman LS, eds. Measures of personality and social psychological attitudes. $3^{\text {rd }}$ ed. Ann Arbor, MI: Institute for Social Research, 1993.

20. Hennekens CH, Buring JE. Epidemiology in Medicine. Boston, MA: Little, Brown and Company; 1987.

21. Bondy SJ, Rehm J, Ashley MJ, Walsh G, Single E, Room R. Low-risk drinking guidelines: the scientific evidence. Can J Public Health 1999;90:264-270.

22. Jones KL, Smith DW. Recognition of the fetal alcohol syndrome in early infancy. Lancet 1973;2:999-1001.

23. Naimi TS, Lipscomb LE, Brewer RD, Gilbert BC. Binge drinking in the preconception period and the risk of unintended pregnancy: implications for women and their children. Pediatrics 2003;111:1136-1141.

24. Knisely JS, Spear ER, Green DJ, Christmas JT, Schnoll SH. Substance abuse patterns in pregnant women. NIDA Res Monogr 1991;105:280-281.

25. Dunty WC Jr, Chen SY, Zucker RM, Dehart DB, Sulik KK. Selective vulnerability of embryonic cell populations to ethanol-induced apoptosis: implications for alcohol-related birth defects and neurodevelopmental disorder. Alcohol Clin Exp Res 2001;25:1523-1535.

26. Sulik KK, Johnston MC. Embryonic origin of holoprosencephaly: interrelationship of the developing brain and face. Scan Electron Microsc 1982;(Pt 1):309-322.

27. Sulik K, Lauder JM, Dehart DB. Brain malformations in prenatal mice following acute maternal ethanol administration. Int J Dev Neurosci 1984;2:203-214.

28. Czeizel AE. Ten years of experience in periconceptional care.Eur J Obstet Gynecol Reprod Biol 1999;84:43-49.

29. Weisman CS, Maccannon DS, Henderson JT, Shortridge E, Orso CL. Contraceptive counseling in managed care: preventing unintended pregnancy in adults. Womens Health Issues 2002;12:79-95.

30. London K Peterson L, Piccinino L. The national survey of family growth: Principal source of statistics on unintended pregnancy (Supplement to chapter). In: Brown SS, Eisenberg L eds. The Best Intentions: Unintended pregnancy and the well-being of children and families. Washington DC: National Academy Press; 1995.

31. Hulsey TM. Association between early prenatal care and mother's intention of and desire for the pregnancy. J Obstet Gynecol Neonatal Nurs 2001;30:275-282.
32. Hellerstedt WL, Pirie PL, Lando HA, Curry SJ, McBride CM, Grothaus LC, Nelson JC. Differences in preconceptional and prenatal behaviors in women with intended and unintended pregnancies. Am J Public Health 1998;88:663-666.

33. Brown SS, Eisenberg L, eds. The Best Intentions: Unintended pregnancy and the well-being of children and families. Washington DC: National Academy Press; 1995.

34. Stanford JB, Hobbs R, Jameson P, DeWitt MJ, Fischer RC. Defining dimensions of pregnancy intendedness. Matern Child Health J 2000;4:183-189.

35. Parker DA, Harford TC, Rosenstock IM. Alcohol, other drugs, and sexual risk-taking among young adults. J Subst Abuse 1994;6:87-93.

36. Wechsler H, Davenport A, Dowdall G, Moeykens B, Castillo S. Health and behavioral consequences of binge drinking in college. A national survey of students at 140 campuses. JAMA 1994;272:1672-1677.

37. Ingersoll K, Floyd L, Sobell M, Velasquez MM; Project CHOICES Intervention Research Group. Reducing the risk of alcohol-exposed pregnancies: a study of a motivational intervention in community settings. Pediatrics 2003; 111:1131-1135.

38. Heyes T, Long S, Mathers N. Preconception care: practice and beliefs of primary care workers. Fam Pract 2004;21:22-27.

39. Tough SC, Clarke M, Hicks M, Clarren S. Clinical practice characteristics and preconception counseling strategies of health care providers who recommend alcohol abstinence during pregnancy. Alcohol Clin Exp Res 2004;28:1724-1731.

40. Kesmodel U, Schioler Kesmodel P. Drinking during pregnancy: attitudes and knowledge among pregnant Danish women, 1998. Alcohol Clin Exp Res 2002;26:1553-1560.

41. Enhart CB, Morrow-Tlucak M, Sokol RJ, Martier S. Underreporting of alcohol use in pregnancy. Alcohol Clin Exp Res 1988;12:506-511.

42. Robles N, Day NL. Recall of alcohol consumption during pregnancy. J Stud Alcohol 1990;51:403-407.

\section{Author Affiliations}

Suzanne Tough, PhD, Department of Pediatrics

Faculty of Medicine, University of Calgary, the

Department of Community Health Sciences

Faculty of Medicine, University of Calgary, and the

Decision Support Research Team, Calgary Health Region

Calgary, Alberta, Canada

Karen Tofflemire, MSc, Decision Support Research

Team, Calgary Health Region

Calgary, Alberta, Canada

Margaret Clarke, $M D$

Department of Pediatrics

Faculty of Medicine, University of Calgary

Calgary, Alberta, Canada

Christine Newburn-Cook, PhD

Faculty of Nursing, University of Alberta

Edmonton, Alberta, Canada 